\author{
Alain Hugon y Alexandra Merle (eds.) \\ Soulèvements, révoltes, révolutions dans l'empire des Habsbourg \\ d'Espagne, XVI'-XVIT siècle \\ Madrid, Casa de Velázquez, 2016, 362 p. \\ ISBN 978-84-9096-055-4
}

\title{
Mathilde Albisson
}

Université Paris 3 Sorbonne Nouvelle (CRES - LECEMO)

mathilde.albisson@sorbonne-nouvelle.fr

Esta esmerada publicación de la Casa de Velázquez, fruto de un ciclo de seminarios organizados en 2013, constituye una valiosa aportación al campo de la historia política de la época moderna. Gracias a vías metodológicas renovadas y planteamientos inéditos, este libro arroja nueva luz sobre acontecimientos que han sido bastante estudiados por la historiografía: los intentos de ruptura con el orden político ocurridos en el imperio de los Habsburgo, desde el reino de Carlos V hasta el de Carlos II. Ahora bien, si los temas no son nuevos sí lo es el enfoque que adoptan las contribuciones de esta publicación, reunidas por Alain Hugon y Alexandra Merle. Este volumen se propone escribir una página de la historia de las rebeliones mediante una perspectiva cultural, esto es, relatar la historia de unos acontecimientos políticos a través de sus producciones culturales (textos, imágenes, discursos, escenificación, ceremonias, etc.).

Como señalan los directores de la publicación en las páginas preliminares, la tríada propuesta en el título — sublevaciones, rebeliones, revoluciones - no agota la variedad de aquellos fenómenos de ruptura política que comparten el anhelo de imponer un cambio en el orden político vigente, bien con la instauración de un sistema de nuevo cuño, bien con la vuelta a un estado anterior, a un pasado mítico en el que se respetaban las libertades y los fueros.

La capacidad de estos movimientos de rebelión de desarrollar, mediante producciones culturales, una argumentación política en torno a las reivindicaciones y unas estructuras de legitimación del sublevamiento constituye el hilo conductor de los trabajos reunidos en este volumen. No todas las rebeliones del 
periodo están representadas (faltan las del Milanesado, Cerdeña, Andalucía y las Comunidades) y algunas están más presentes que otras, pues el propósito de este libro no ha sido el de escribir la historia exhaustiva de las rebeliones en el imperio hispánico sino el de comprobar fenómenos recurrentes en el uso de productos culturales, fenómenos que sintetizan Alain Hugon y Alexandra Merle en las páginas de conclusiones que cierran esta publicación.

Los 15 artículos de los que consta el libro — diez de ellos en castellano, los restantes en francés - están organizados en cuatro bloques temáticos. El primero está dedicado a las fuentes, soportes y medios que vehiculaban ciertos códigos y presupuestos que rebeldes y autoridades usaban o recusaban (fuentes judiciarias, pasquines, producciones efímeras, correspondencias, etc.). Los artículos que conforman el segundo bloque estudian las «herramientas de la política», es decir, las modalidades de redacción de la información, así como los canales empleados para su difusión y transmisión. En el tercer grupo se recoge une serie de estudios sobre los rituales y ceremoniales comunitarios que constituyeron elementos clave para la adquisición y conservación de la legitimidad política. Los autores atienden tanto a su uso como a los intentos de eliminación por parte de las fuerzas contrarias. El último bloque lo integran trabajos sobre la circulación de los modelos políticos y la manera en que las ideas y nociones se reutilizaban y transformaban según las necesidades políticas del momento. Con estos artículos finales se comprueba que la recuperación de modelos de una rebelión para aplicarlos a otra no excluía la producción de innovaciones, voluntarias o no, en el seno de dichos modelos.

El primer grupo se abre con un estudio de Manfredi Merluzzi sobre la representación identitaria de los insurrectos pizarristas en la rebelión que tuvo lugar en el Perú entre 1543 y 1548, contra las ordenanzas de Carlos V. El autor observa cómo se va transformando tal representación mediante un análisis del léxico empleado en diferentes actos de comunicación (textos oficiales, correspondencia, actos públicos, crónicas, etc.). Merluzzi hace hincapié en el esfuerzo constante de los insurgentes por legitimar su acción y fundar jurídicamente en cada etapa sus pretensiones, apelando a un principio o una institución del sistema jurídico vigente. Este estudio deja perfectamente claro el paso progresivo de las declaraciones iniciales de fidelidad de unos súbditos que apelan al «rey justiciero», hacia la ruptura con el orden jurídico y la incriminación de la propia corona.

En el siguiente artículo Michèle Guillemont analiza los acontecimientos ocurridos en Paraguay en 1649, nacidos del enfrentamiento entre el obispo de Asunción, los jesuitas y el cabildo asunceno, que apoyó alternativamente al obispo y a la Compañía de Jesús. Tras una minuciosa restitución cronológica de los sucesos, la investigadora se centra en las acusaciones de usurpación de la autoridad civil que emanaron de los dos bandos. Mientras que los escritos defensorios del obispo intentaban acreditar que nunca se levantó contra la autoridad del virrey, la producción documental jesuita aludía en cambio al fomento de una rebelión por parte del prelado. Guillemont termina examinando la posición que 
frente a los sucesos asuncenos adoptaron, por un lado, el poder virreinal y, por otro, la metrópoli, que optó por acallar la contienda ordenando la recogida de los escritos en que las partes se agraviaban. La autora presta especial atención a la «batalla documental» que corrió pareja a la lucha política, en la cual se percibe la importancia del documento a la vez como arma que atiza la contienda y como elemento legitimador.

Jesús Gascón Pérez estudia un corpus de pasquines y panfletos que circularon con motivo de la rebelión de 1591 en el reino de Aragón. El autor contrasta la visión que ofrecen los textos apologéticos escritos después de la sublevación, que alababan la inquebrantable fidelidad de los aragoneses, rehusando el marbete de 'rebelión', con la realidad representada en esos textos propagandísticos de los que se valió la oposición política aragonesa para denunciar una praxis de gobierno que no respetaba el ordenamiento foral y para defender su derecho de resistencia ante un monarca 'tiránico'. Esta rebelión, como observa acertadamente el investigador, distó de ser un acontecimiento inconexo. Por un lado, señala la existencia continuada en Aragón de una corriente de pensamiento político que en algunos momentos llegó a estructurar movimientos de resistencia, de los cuales el de 1591 fue el que mayor relevancia tuvo.

El primer bloque se cierra con un artículo de Mathias Ledroit que revisa las posiciones historiográficas que consideran las matanzas acaecidas en Barcelona como el punto de arranque de la revuelta de 1640. Sin minimizar este suceso, el estudioso reconsidera las repercusiones que tuvo el bombardeo de Perpińán en el proceso que llevó a la desunión entre la monarquía y las instituciones catalanas. En primer lugar, reconstruye el contexto en el que se produjo el bombardeo de la ciudad, marcado por la hostilidad entre catalanes y militares. Fijándose en el periodo comprendido entre las últimas tentativas de restauración del orden y la invasión de Cataluña, el autor ahonda en la reacción del gobierno real y de las instituciones catalanas, que recelaban que el bombardeo formase parte de una estrategia destinada a conquistar Cataluña. Ledroit dedica la última parte del artículo a estudiar cómo, unos meses antes de la ruptura definitiva, los propagandistas del Consell de Cent integraron en sus manifiestos el bombardeo de Perpiñán, convertido en el «símbolo de la tiránica barbarie», para justificar la guerra de resistencia contra Felipe IV.

Sin abandonar el campo de las rebeliones, Francesco Benigno realiza una acertada crítica de tres modelos que considera inválidos para interpretar la comunicación política de la Primera Edad Moderna, contraponiéndolos con la realidad social de la Sicilia del siglo xviı. Además de señalar la existencia de un grupo poderoso de nobles que participaba activamente en la comunicación política, el investigador resalta el papel de primera línea desempeñado por las capas populares en las rebeliones de Palermo de 1647 y de Mesina de 1674. El ejemplo de la politizada sociedad siciliana le sirve a Benigno para demostrar que participación, comunicación y movilización políticas no fueron una prerrogativa exclusiva del rey ni de un estamento único. 
En su contribución, Juan Carlos D’Amico aborda los medios de comunicación y difusión de las reivindicaciones en la revuelta napolitana de 1547. Las motivaciones religiosas de la rebelión muy pronto dieron paso a una meta política: la destitución del virrey, que había mermado el poder de la nobleza y del gobierno local. Tras señalar esta doble vertiente de los motivos de los insurgentes, D’Amico destaca la función desempeñada en la sublevación por la comunicación escrita y oral así como la relevancia de los carteles en la justificación de la rebelión y en el intento de propagarla. A través de un minucioso estudio de la correspondencia conservada en el Archivo de Simancas, el autor dilucida las estrategias empleadas por el virrey para impedir la circulación de las ideas subversivas en el espacio público del reino y en la corte de Carlos V.

Joana Fraga y Joan-Lluís Palos ofrecen un estudio comparado de la producción de imágenes que generaron tres sublevamientos ocurridos en los años 1640 en Cataluña, Portugal y Nápoles. La capacidad de movilización limitada del texto impreso explica la necesidad que tuvieron los insurrectos de crear imágenes para llegar a las sensibilidades y suscitar adhesiones. Una parte de este estudio está dedicada a la construcción visual de liderazgos alternativos al del monarca español, subordinada a la búsqueda de una figura capaz de galvanizar las aspiraciones y la reverencia de los insurrectos. Las autoridades españolas, conscientes del poder de esas imágenes, emprendieron su recogida, destrucción e incluso su compra, lo que explica en parte el carácter fragmentario del corpus visual conservado.

Julie Versele emprende el estudio de las vías de transmisión de las ideas subversivas durante la rebelión de los Países Bajos. Tras recordar los fundamentos político-religiosos de la revuelta, la autora se fija en una serie de documentos que divide en función de su contenido y del público al que se dirigían. Atiende primero a los soportes de la argumentación teórica y jurídica de la revuelta, pasando después a investigar los modos de difusión de las ideas subversivas entre un público más popular y completa esta parte con la reproducción y el comentario de una serie de caricaturas y alegorías. Hace también una breve pero sugestiva incursión en la cuestión de los impresores de textos sediciosos, entre los cuales figuraba el célebre tipógrafo Plantino. Se centra por último en los intentos de las autoridades para poner coto a la corriente de ideas de los insurrectos, como la extensión de la vigilancia de la imprenta y del comercio del libro o el recurso a una contra-propaganda.

Héloïse Hermant se acerca a la rebelión de los Barretines (1687-1690) a través de los libelos, manifiestos y pasquines de los insurrectos. Subraya la dificultad que supone la reconstrucción de esta producción textual, por tratarse de textos efímeros, que no fueron pensados para ser conservados. La estudiosa identifica los momentos de gran florecimiento escritural, que se corresponden con los momentos de mayor tensión y con acontecimientos precisos. De hecho, la autora entiende que esta literatura de combate siempre funcionó en ósmosis y no en oposición con las acciones de los insurgentes. Insiste también en la rela- 
ción de intertextualidad que vinculaba los textos de los Barretines entre sí y en su conexión con los documentos que procedían de las instituciones reales y barcelonesas, con los que dialogaban.

Inaugura el tercer bloque la contribución de Ida Mauro, dedicada al estudio del sistema ceremonial orquestado por el conde de Ońate en el virreinato de Nápoles. La autora describe las diferentes estrategias empleadas por el virrey después de la rebelión de 1647 para transmitir una imagen de firmeza de la monarquía restaurada: control de las ceremonias urbanas, militarización de la ciudad, ostentación de los símbolos regios, teatralización de la justicia, orquestación del carnaval, reglamentación de las fiestas. El conde de Oñate logró así monopolizar el espacio urbano y disciplinar lo que había constituido el escenario de la revuelta.

Rafael Valladares nos brinda un curioso caso de manipulación política. Coteja dos versiones manuscritas de la relación del carnaval de Lisboa de 1666, para las que propone una interpretación distinta de la del profesor Fernando Bouza, empezando por dudar de que los hechos referidos en ambos textos correspondan a un carnaval e incluso ocurrieran de verdad. Considera que esta fiesta, verdadera o literaria, además de celebrar la victoria de los Braganza sobre Felipe IV, formaba parte del programa de exaltación del régimen bragancista y de legitimación política de Alfonso VI. Al final del artículo, Valladares ofrece la transcripción de ambas versiones.

El último artículo del tercer bloque está dedicado a la propaganda de los exiliados filipistas de la Guerra de Cataluńa, refugiados en Madrid entre los años 1640 y 1652. Diana Carrió-Invernizzi investiga la manera en que este grupo se organizó para conseguir ayudas y cómo llegó a movilizarse para ganar influencia ampliando los espacios de representación de su comunidad en la villa. La autora se detiene en dos ejemplos significativos: el Hospital de los Aragoneses y el monasterio de los monjes expulsados de Montserrat. Ubica esas iniciativas, en las que se aprecia una clara conciencia de grupo, en el debate político iniciado en los ańos cuarenta en torno a la integración territorial en la monarquía y a la mayor o menor participación que debían tener los catalanes y los portugueses en los Consejos de la monarquía.

Manuel Herrero Sánchez centra su atención en el peso político de las ciudades en la Monarquía hispánica, haciendo hincapié en el papel fundamental que desempeñaron en el mantenimiento del sistema imperial. Pese a los episodios revolucionarios que protagonizaron, las ciudades trabaron formas de colaboración con el rey que vinculaban sus intereses al de la política del imperio. La garantía de un amplio margen de autonomía explica la relativa estabilidad social de esta «monarquía de ciudades» dispersas. Rebatiendo la posición historiográfica que defiende un profundo antagonismo entre Monarquía hispánica y repúblicas, el autor considera que aquellos acontecimientos revolucionarios fueron motivados en gran medida por las erosiones del consenso entre la Monarquía y las ciudades y se resolvieron siempre mediante una reactualización del pacto. En base a esta 
constatación, concluye que el modelo de repúblicas urbanas no fue una mera alternativa al sistema monárquico sino la vía que aparecía como la más adecuada para resolver el conflicto.

Joaquím Albareda relaciona tres episodios de insurrección, basándose en la concepción política que compartían los rebeldes: la defensa del constitucionalismo catalán. En la revuelta de los Barretines, detecta la existencia inequívoca de una política en pro del «bien público», en la cual el hombre común participaba mediante la reivindicación y la negociación apelando a las Constituciones catalanas. Albareda sostiene que el constitucionalismo catalán fue uno de los aspectos fundamentales de la oposición a Felipe V, que entró en liza en la contienda de 1705, en la medida en que chocaba con el proyecto filipista. En los últimos años de la Guerra de Sucesión (1713-1714), que el autor califica de «momento republicano", fue cuando la defensa de las libertades plasmadas en las Constituciones pasó al primer plano y el discurso político evolucionó hacia posiciones republicanas. El abandono del bando austracista abrió paso a la opción de una república catalana, que no llegó a contar con suficiente respaldo.

El volumen se cierra con la contribución de Clizia Magoni que versa sobre la circulación y utilización del modelo político aragonés en la Europa moderna, que llegó a convertirse en un ejemplo de referencia en la literatura de combate y en argumento funcional en situaciones de conflicto que oponían los súbditos al poder real. La autora rastrea los orígenes de este modelo de gobierno y analiza una serie de textos que contribuyeron a vertebrar el mito de la constitución aragonesa. Menciona a este respecto el papel desempeñado por Alonso Pérez en su construcción y en su difusión en Europa. Esboza un interesante panorama de las variadas utilizaciones del ejemplo aragonés desde los tratados monarcómacos, pasando por el pensamiento político de los Whigs y de la Revolución francesa hasta el Risorgimento italiano. El estudio pone de manifiesto que el modelo aragonés encarnó un sistema de valores que se prestó a interpretaciones nuevas, enriqueciéndose cada vez de nuevos significados.

En suma, este volumen ofrece, gracias a vías metodológicas renovadas, una visión inédita de aquellos acontecimientos conflictivos que ponían en tela de juicio el orden político vigente en la Monarquía de los Habsburgo. En la actualidad varios equipos están trabajando desde estos nuevos enfoques metodológicos para leer las rebeliones a través de la iconografía, la escritura, la comunicación política y la circulación y difusión de la información y de los modelos políticos. Se trata de perspectivas prometedoras que seguramente nos deparen frutos sugerentes y originales como este libro. 